\title{
A Case of Acute Coronary Syndrome and Ischemic Stroke After Symptomatic Resolution of COVID-19
}

\section{Samuel D. Rose ( $\nabla$ srose@bronxcare.org )}

BronxCare Health System

\section{Andrew Salama}

BronxCare Health System

Jonathan N. Bella

BronxCare Health System

\section{Sridhar Chilimuri}

BronxCare Health System

\section{Case report}

Keywords: COVID-19, SARS-CoV-2, thrombosis, coagulopathy, acute coronary syndrome, ischemic stroke

Posted Date: July 9th, 2021

DOI: https://doi.org/10.21203/rs.3.rs-665102/v1

License: (9) This work is licensed under a Creative Commons Attribution 4.0 International License. Read Full License 


\section{Abstract}

Background:

There is increasing evidence that thromboembolic events are a major cause of morbidity and mortality in COVID-19 patients. We present a case with two suspected thromboembolic events - acute coronary and ischemic stroke - after the resolution of infectious symptoms.

Case Presentation:

A 66-year-old male presented to the emergency department complaining of sudden onset of vision loss. He had no known medical history, but two weeks earlier presented to an outside hospital with fevers and was diagnosed with COVID-19. Brain CT revealed bilateral posterior cerebral artery territory infarcts, with subsequent MRA showing basilar artery attenuation as a likely source of embolization. Additionally, Troponin T was moderately elevated on admission $(155 \mathrm{ng} / \mathrm{ml})$ and reached a peak $(1025 \mathrm{ng} / \mathrm{mL})$ at 24 hours. Serial EKG showed dynamic changes since admission but the patient refused full cardiac workup. He was treated with dual anti-platelet therapy, high-intensity statin and ACE-inhibitor and was discharged with a stable visual deficit.

Conclusions:

A systemic coagulopathy from COVID-19 most likely caused two thromboembolic events in this patient. This case highlights the complex manifestations of coagulopathy caused by COVID-19 and the need for monitoring and treatment of thromboembolic events beyond the resolution of the acute infectious syndrome.

\section{Case Presentation}

A 66-year-old male presented to the emergency department complaining of sudden onset of vision loss. He had no known medical history but was evaluated for fever two weeks ago at an outside hospital. The patient and his daughter tested positive for COVID-19 and were advised to stay at home. The fevers resolved but he then experienced sudden bilateral vision impairment two days before returning to the hospital. He reported almost complete loss of vision at the time of onset, although on presentation he could see well enough to make phone calls. The patient also complained of a mild bilateral temporal headache. He denied any chest pain, palpitations, or shortness of breath. The patient had no prior episodes of vision loss.

On admission the patient was afebrile with a blood pressure of $145 / 86 \mathrm{mmHg}$ and pulse of $98 \mathrm{bpm}$. Respiration rate (18 bpm) and oxygen saturation ( $99 \%$ on room air) were normal. He was fully oriented and able to follow commands without any weakness or sensory deficit. Pupils were equal, round, and reactive to light but he was unable to track movement, count fingers, or read at any distance. 
Labs (Table 1) revealed normal CBC with elevations of serum D-dimer $(770 \mathrm{mcg} / \mathrm{mL}), \mathrm{LDH}$ (244 units/L), and ferritin $(474.1 \mathrm{ng} / \mathrm{mL})$. ESR $(108 \mathrm{~mm} / \mathrm{hr})$ and CRP $(22.9 \mathrm{mg} / \mathrm{L})$ were both elevated. He had moderately prolonged APTT $(38.1 \mathrm{sec})$ with normal PT/INR $(12.8 \mathrm{sec} / 1.08)$. Hemoglobin A1c was found to be elevated (7.8\%) with normal lipid profile. On of admission Troponin T was moderately elevated (155 $\mathrm{ng} / \mathrm{ml})$ and subsequent labs showed elevation to a peak (1025 ng/mL) at 24 hours. Chest X-Ray (Fig. 1) revealed bilateral airspace disease. EKG on admission was unable to be located but documented to show normal sinus rhythm. Serial EKG at 24 hours (Fig. 2) showed dynamic changes with new non-specific ST/T-wave changes, T-wave inversions in leads V4-6, and T-wave abnormalities in II, III, aVF. CT head on day of admission (Fig. 3A) showed bilateral posterior cerebral artery territory infarcts and MRI brain on hospital day three (Fig. 3B) confirmed bilateral acute infractions within the posterior circulation. MRA on hospital day three (Fig. 3C) showed left vertebral artery stenosis at the level of the foramen magnum. Cardiac echo showed mild left ventricular dysfunction but the patient refused additional cardiac workup.

The patient was treated with dual anti-platelet therapy and started on high-intensity statin and ACEinhibitor. He was discharged with a stable visual deficit on the fifth day of hospitalization.

\section{Discussion}

There is increasing evidence that thromboembolic events are a major cause of morbidity and mortality in COVID-19 patients (1). While severe infection often affects patients with independent risk factors such as diabetes, hypertension, advanced age, and pulmonary disease, $(2,3)$ reports have shown an increased risk of thrombosis in COVID-19 patients as compared with controls admitted to the same level of inpatient care $(4,5)$, so there appears to be a disease-specific effect.

COVID-19 hypercoagulability is likely multifactorial, but seems tied to the inflammatory response and immunocompromised individuals have been suggested to have fewer pulmonary complications when infected with the virus (6). While the underlying pathophysiology remains to be fully understood, a particular concern is the pro-inflammatory "cytokine storm" ( 7$)$, activating many endogenous triggers of coagulation. Of note, infection is associated with increased inflammatory markers such D-dimer, fibrin, interleukin-6 (IL-6), tumor necrosis factor-a (TNF-a) and fibrinogen-degradation products (8-10). This inflammatory state is thought to promote hypercoagulation through mechanisms including up-regulation of tissue factor, thereby triggering the intrinsic and extrinsic coagulation pathways (11). D-dimer has also been suggested as a predictive marker of severe illness $(12,13)$, so its value as a measure of coagulopathy in this setting is unknown.

Recent studies have also implicated the role of neutrophils via production of neutrophil-derived extracellular traps (NETs) - composed of proteins and extracellular DNA - in the pathologic thrombosis seen COVID-19. While NET formation is known to aid in the clearance of bacterial and viral pathogens, dysregulation of this process by respiratory viruses such as SARS-CoV2 is thought to promote microvascular thrombosis and end-organ damage (14). Elevated circulating levels of NETs have been 
shown in serum of COVID-19 patients (15) and post-mortem analysis samples from lungs of COVID-19 patients have shown extensive neutrophil infiltration of the pulmonary vascular and alveolar space (16).

In addition to these systemic effects, there is evidence that SARS-CoV-2 can induce microthrombosis by direct invasion of endothelial cells via the ACE-2 (angiotensin-converting enzyme 2) receptor, which is expressed on the endothelial cell surface, and post-mortem analysis ofvarious organ tissue have shown viral inclusion structures in endothelial cells of COVID-19 patients (17). Viral invasion of the endothelium is thought to disrupt the innate fibrinolytic function of these cells, predisposing to local thrombus formation (18).

Endothelial dysfunction may explain several important observations. For example, clinical and postmortem studies have shown the absence of DVT in most COVID-19 patients with pulmonary vascular obstruction, suggesting that pulmonary thrombi in COVID-19 patients may often result from local hypercoagulability, rather than embolization from the lower limbs $(19,20)$. Additionally, cardiac microthrombi in the absence of epicardial coronary occlusion appear as hallmarks of COVID-19 (21), and therefore also likely represent local hypercoagulability.

In the case we present, the patient had two clinically significant intravascular sequelae of COVID-19 affecting posterior cerebral and coronary arteries. With regards to the CVA, a cardioembolic origin was unlikely due to bilateral involvement of the cerebral vasculature. Additionally, MRA revealed left vertebral artery attenuation, which is a likely source of embolization to this region. We therefore suspect disruption of a longstanding atherosclerotic plaque as the mechanism of posterior cerebral ischemia. The mechanism for troponin elevation, however, is unclear given the absence of coronary imaging, but could relate to thrombo-embolic or microvascular processes as previously discussed.

The timeline in this case is revealing and consistent with observations that thromboembolic risk of SARSCoV-2 persists substantially longer than the infectious symptoms. In fact, a new disease entity, termed multisystem inflammatory syndrome in adults (MIS-A) (22), has emerged to describe the diverse extrapulmonary manifestations of SARS-CoV-2 in the days to weeks following the resolution of the acute illness. MIS-A is defined by severe dysfunction of one or more extrapulmonary systems - in the absence of respiratory symptoms - with elevated inflammatory markers and laboratory evidence SARS-CoV-2 infection (22), as seen in the case we present. An important component of MIS-A appears to be a persistently elevated risk of thromboembolic events and case reports highlight findings of large vessel stroke (23) and cardiac complications (24) in otherwise low-risk patients. Post-mortem studies have shown small vessel vasculitis and endotheliitis as the cause of end-organ dysfunction, reflecting an inflammatory process.

While many institutions have adopted guidelines for continued anticoagulation in high-risk patient following hospital discharge (12), these findings raise interesting questions about the role of antiinflammatory treatment in the prevention of post-COVID-19 sequelae. 


\section{Abbreviations}

CVA: Cerebrovascular accident

CBC: complete blood count

CT: computerized tomography

MRI: magnetic resonance imaging

MRA: magnetic resonance angiography

\section{Declarations}

\section{Availability of data and materials:}

Not applicable

\section{Ethics Approval:}

Not applicable

\section{Consent for publication:}

Obtained from patient

\section{Competing Interests:}

The authors declare that they have no competing interests.

\section{Funding:}

Not applicable

\section{Authors' Contributions:}

SR performed review of literature and drafted manuscript. AS and JB made revisions to intellectual content. SC advised on drafting of manuscript, made revisions to intellectual content, and approved final draft for submission.

\section{References}


1. Klok F, Kruip M, van der Meer N, Arbous M, Gommers D, Kant K et al. Incidence of thrombotic complications in critically ill ICU patients with COVID-19. Thrombosis Research. 2020;191:145-147.

2. Yang J, Zheng Y, Gou X, Pu K, Chen Z, Guo Q et al. Prevalence of comorbidities and its effects in patients infected with SARS-CoV-2: a systematic review and meta-analysis. International Journal of Infectious Diseases. 2020;94:91-95.

3. Grasselli G, Zangrillo A, Zanella A, Antonelli M, Cabrini L, Castelli A et al. Baseline Characteristics and Outcomes of 1591 Patients Infected With SARS-CoV-2 Admitted to ICUs of the Lombardy Region, Italy. JAMA. 2020;323(16):1574.

4. Helms J, Tacquard C, Severac F, Leonard-Lorant I, Ohana M, Delabranche X et al. High risk of thrombosis in patients with severe SARS-CoV-2 infection: a multicenter prospective cohort study. Intensive Care Medicine. 2020;46(6):1089-1098.

5. Poissy J, Goutay J, Caplan M, Parmentier E, Duburcq T, Lassalle F et al. Pulmonary Embolism in Patients With COVID-19. Circulation. 2020;142(2):184-186.

6. Thachil J, Srivastava A. SARS-2 Coronavirus-Associated Hemostatic Lung Abnormality in COVID-19: Is It Pulmonary Thrombosis or Pulmonary Embolism?. Seminars in Thrombosis and Hemostasis. 2020;46(07):777-780.

7. Mehta P, McAuley D, Brown M, Sanchez E, Tattersall R, Manson J. COVID-19: consider cytokine storm syndromes and immunosuppression. The Lancet. 2020;395(10229):1033-1034.

8. Lippi G, Favaloro E. D-dimer is Associated with Severity of Coronavirus Disease 2019: A Pooled Analysis. Thrombosis and Haemostasis. 2020;120(05):876-878.

9. Zhou F, Yu T, Du R, Fan G, Liu Y, Liu Z et al. Clinical course and risk factors for mortality of adult inpatients with COVID-19 in Wuhan, China: a retrospective cohort study. The Lancet. 2020;395(10229):1054-1062.

10. Chen G, Wu D, Guo W, Cao Y, Huang D, Wang H et al. Clinical and immunological features of severe and moderate coronavirus disease 2019. Journal of Clinical Investigation. 2020;130(5):2620-2629.

11. Price L, McCabe C, Garfield B, Wort S. Thrombosis and COVID-19 pneumonia: the clot thickens!. European Respiratory Journal. 2020;56(1):2001608.

12. Cohoon K, Mahé G, Tafur A, Spyropoulos A. Emergence of institutional antithrombotic protocols for coronavirus 2019. Research and Practice in Thrombosis and Haemostasis. 2020;4(4):510-517.

13. Connors J, Levy J. COVID-19 and its implications for thrombosis and anticoagulation. Blood. 2020;135(23):2033-2040. 
14. Middleton E, He X, Denorme F, Campbell R, $\mathrm{Ng} \mathrm{D}$, Salvatore $\mathrm{S}$ et al. Neutrophil extracellular traps contribute to immunothrombosis in COVID-19 acute respiratory distress syndrome. Blood. 2020;136(10):1169-1179.

15. Zuo Y, Zuo M, Yalavarthi S, Gockman K, Madison J, Shi H et al. Neutrophil extracellular traps and thrombosis in COVID-19. Journal of Thrombosis and Thrombolysis. 2020;51(2):446-453.

16. Barnes B, Adrover J, Baxter-Stoltzfus A, Borczuk A, Cools-Lartigue J, Crawford J et al. Targeting potential drivers of COVID-19: Neutrophil extracellular traps. Journal of Experimental Medicine. 2020;217(6).

17. Varga Z, Flammer A, Steiger P, Haberecker $M$, Andermatt $R$, Zinkernagel A et al. Endothelial cell infection and endotheliitis in COVID-19. The Lancet. 2020;395(10234):1417-1418.

18. Ahmed S, Zimba O, Gasparyan A. Thrombosis in Coronavirus disease 2019 (COVID-19) through the prism of Virchow's triad. Clinical Rheumatology. 2020;39(9):2529-2543.

19. Thachil J, Srivastava A. SARS-2 Coronavirus-Associated Hemostatic Lung Abnormality in COVID-19: Is It Pulmonary Thrombosis or Pulmonary Embolism?. Seminars in Thrombosis and Hemostasis. 2020;46(07):777-780.

20. Fox S, Akmatbekov A, Harbert J, Li G, Quincy Brown J, Vander Heide R. Pulmonary and cardiac pathology in African American patients with COVID-19: an autopsy series from New Orleans. The Lancet Respiratory Medicine. 2020;8(7):681-686.

21. Guagliumi G, Sonzogni A, Pescetelli I, Pellegrini D, Finn A. Microthrombi and ST-Segment-Elevation Myocardial Infarction in COVID-19. Circulation. 2020;142(8):804-809.

22. Morris S, Schwartz N, Patel P, Abbo L, Beauchamps L, Balan S et al. Case Series of Multisystem Inflammatory Syndrome in Adults Associated with SARS-CoV-2 Infection - United Kingdom and United States, March-August 2020. MMWR Morbidity and Mortality Weekly Report. 2020;69(40):1450-1456.

23. Oxley T, Mocco J, Majidi S, Kellner C, Shoirah H, Singh I et al. Large-Vessel Stroke as a Presenting Feature of Covid-19 in the Young. New England Journal of Medicine. 2020;382(20):e60.

24. Chau V, Giustino G, Mahmood K, Oliveros E, Neibart E, Oloomi M et al. Cardiogenic Shock and Hyperinflammatory Syndrome in Young Males With COVID-19. Circulation: Heart Failure. 2020;13(10).

\section{Tables}


Table 1. Relevant laboratory results.

$\begin{array}{ll}\text { WBC } & 12.9 \mathrm{k} / \mathrm{ul} \\ \text { Abs lymphocyte count } & 1.6 \mathrm{k} / \mathrm{ul} \\ \mathrm{RBC} & 4.18 \mathrm{MIL} / \mathrm{ul} \\ \mathrm{Hgb} & 12.9 \mathrm{~g} / \mathrm{dL} \\ \mathrm{Plt} & 444 \mathrm{k} / \mathrm{ul} \\ \mathrm{Na} & 135 \mathrm{mEq} / \mathrm{L} \\ \mathrm{K} & 4.5 \mathrm{mEq} / \mathrm{L} \\ \mathrm{Glc} & 266 \mathrm{mg} / \mathrm{dL} \\ \text { D-dimer } & 770 \mathrm{mcg} / \mathrm{mL} \\ \text { LDH } & 244 \mathrm{unils} / \mathrm{L} \\ \text { ferritin } & 474.1 \mathrm{ng} / \mathrm{mL} \\ \text { ESR } & 108 \mathrm{~mm} / \mathrm{hr} \\ \text { CRP } & 22.9 \mathrm{mg} / \mathrm{L} \\ \text { APTT } & 38.1 \mathrm{sec} \\ \text { PT/INR } & 12.8 \mathrm{sec} / 1.88 \\ \text { Hemoglobin Alc } & 7.80 \% \\ \text { Cholesterol, serum } & 137 \mathrm{mg} / \mathrm{dL} \\ \text { LDL } & 82 \mathrm{mg} / \mathrm{dL} \\ \text { HDL } & 30 \mathrm{mg} / \mathrm{dL} \\ \text { TG } & 125 \mathrm{mg} / \mathrm{dL} \\ \text { Pro-BNP } & 1937 \mathrm{pg} / \mathrm{mL} \\ \text { Troponin T (admission) } & 155 \mathrm{ng} / \mathrm{mL} \\ \text { Troponin T peak (24h) } & 1025 \mathrm{ng} / \mathrm{mL}\end{array}$

Figures 


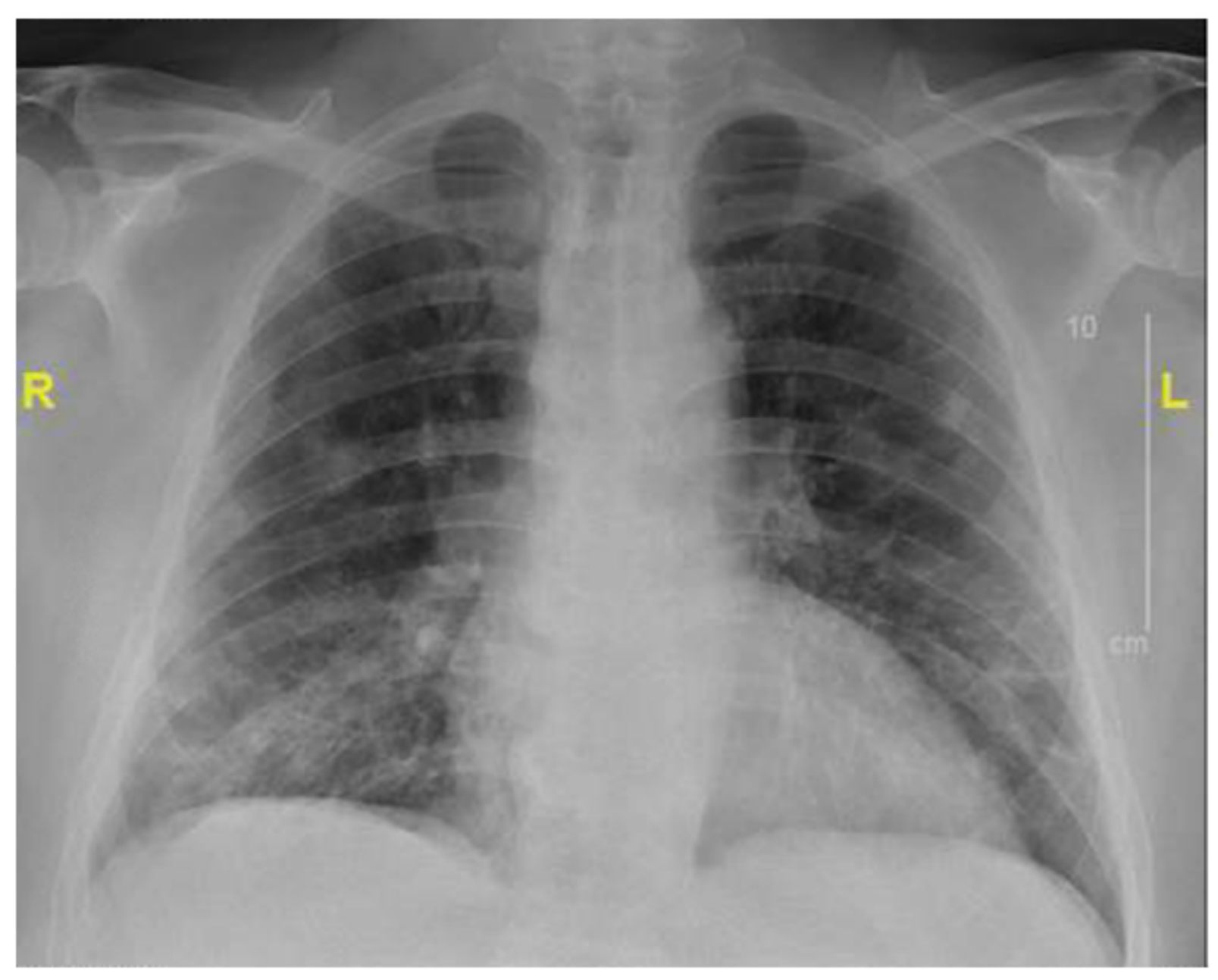

Figure 1

Chest X-Ray showed bilateral airspace disease consistent with Covid-19. 


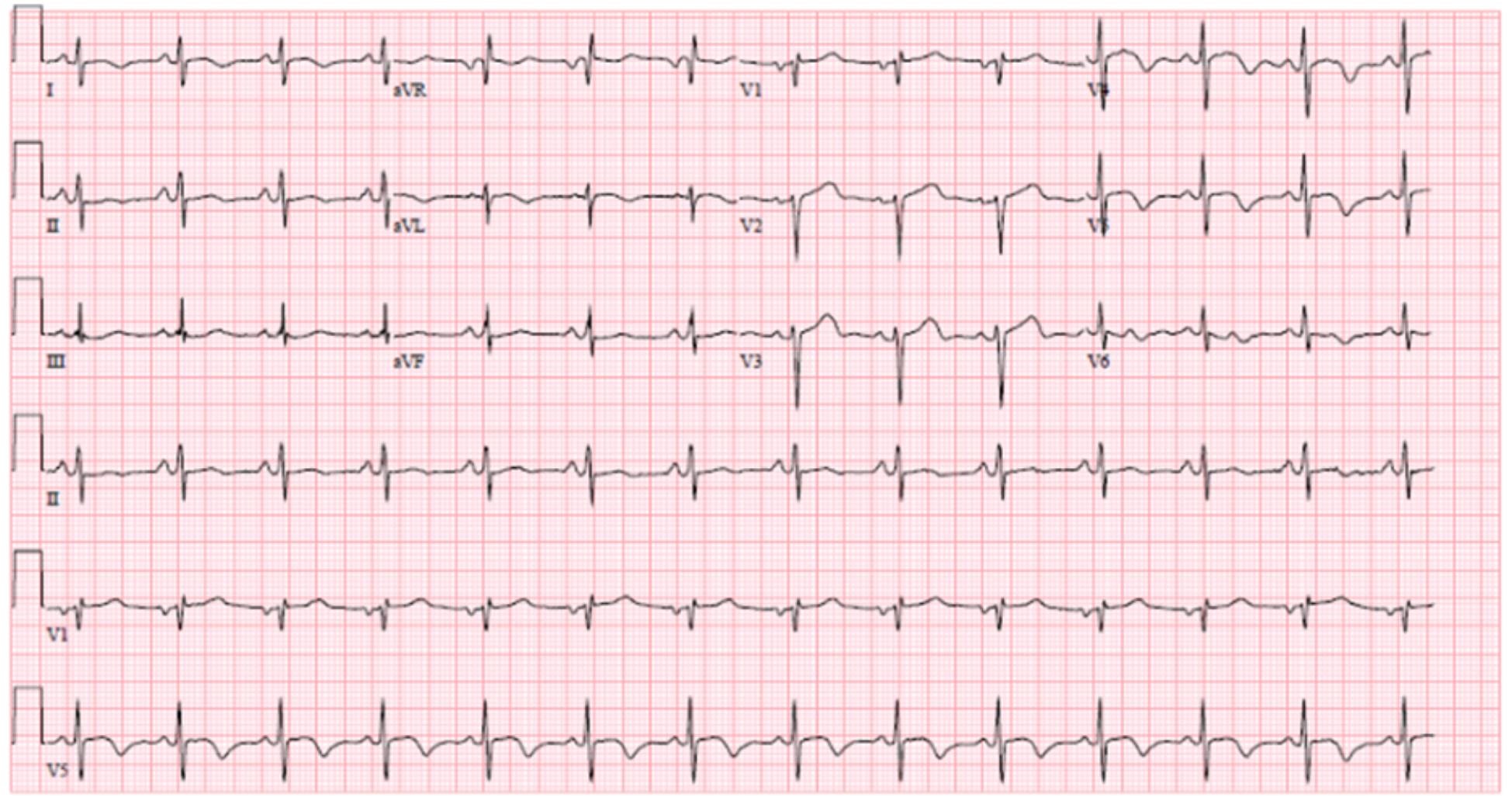

Figure 2

Serial EKG after 24 hours showed dynamic changes from admission: Non-specific ST/T-wave changes, Twave abnormalities in II, III, aVF, and T-wave inversions in V4-6.

CT

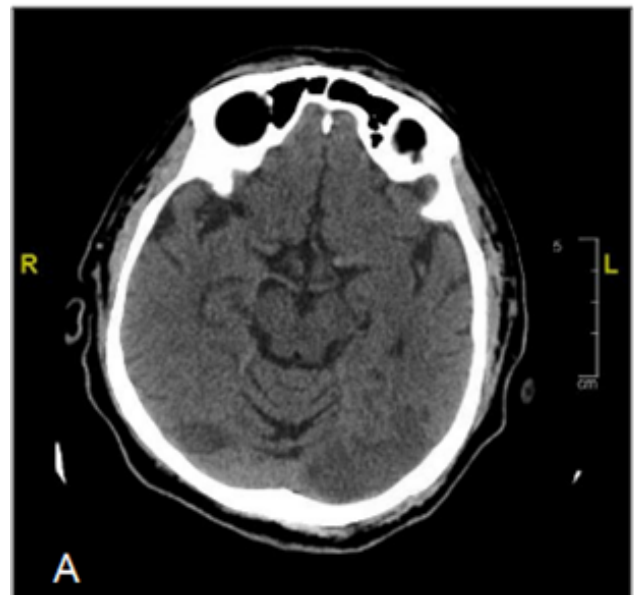

MRI

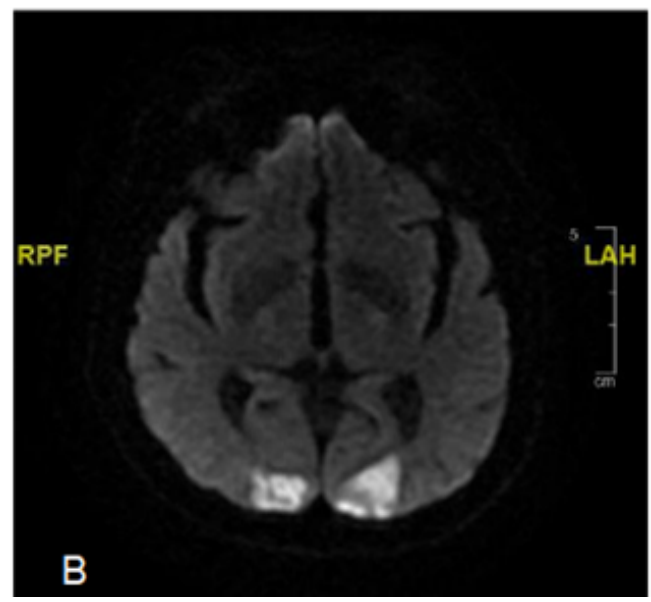

MRA

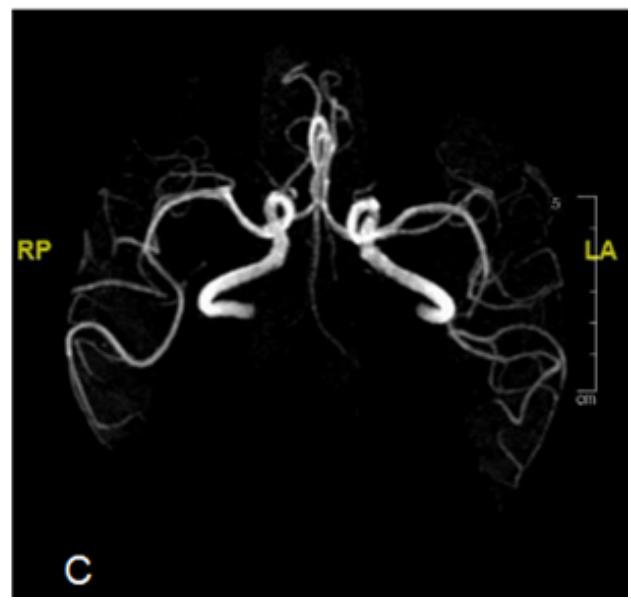

Figure 3

Brain Imaging. (A) CT on the day of admission showed bilateral posterior cerebral artery territory infarcts.

(B) MRI on hospital day 3 confirmed multiple bilateral infractions within the occipital lobe, hippocampal formations, and cerebellar hemispheres. (C) MRA on hospital day 3 showed left vertebral artery attenuation at the level of the foramen magnum. 